\title{
Digital versus conventional techniques for pattern fabrication of implant-supported frameworks
}

\author{
Marzieh Alikhasi ${ }^{1}$, Ahmad Rohanian $^{1}$, Safoura Ghodsi ${ }^{1}$, Amin Mohammadpour Kolde $^{2}$
}

Correspondence: Dr. Safoura Ghodsi

Email: safura_gh82@yahoo.com

\begin{abstract}
'Dental Research Center, Dentistry Research Institute and Department of Prosthodontics, School of Dentistry, Tehran University of Medical Sciences, Tehran, Iran,

${ }^{2}$ Dental Student Research Center, School of Dentistry, Tehran University of Medical Sciences, Tehran, Iran
\end{abstract}

\section{ABSTRACT}

Objective: The aim of this experimental study was to compare retention of frameworks cast from wax patterns fabricated by three different methods. Materials and Methods: Thirty-six implant analogs connected to one-piece abutments were divided randomly into three groups according to the wax pattern fabrication method $(n=12)$. Computer-aided design/computer-aided manufacturing $(\mathrm{CAD} / \mathrm{CAM})$ milling machine, three-dimensional printer, and conventional technique were used for fabrication of waxing patterns. All laboratory procedures were performed by an expert-reliable technician to eliminate intra-operator bias. The wax patterns were cast, finished, and seated on related abutment analogs. The number of adjustment times was recorded and analyzed by Kruskal-Wallis test. Frameworks were cemented on the corresponding analogs with zinc phosphate cement and tensile resistance test was used to measure retention value. Statistical Analysis Used: One-way analysis of variance (ANOVA) and post hoc Tukey tests were used for statistical analysis. Level of significance was set at $P<0.05$. Results: The mean retentive values of $680.36 \pm 21.93 \mathrm{~N}, 440.48 \pm 85.98 \mathrm{~N}$, and $407.23 \pm 67.48 \mathrm{~N}$ were recorded for CAD/CAM, rapid prototyping, and conventional group, respectively. One-way ANOVA test revealed significant differences among the three groups $(P<0.001)$. The post hoc Tukey test showed significantly higher retention for CAD/CAM group $(P<0.001)$, while there was no significant difference between the two other groups $(P=0.54)$. CAD/CAM group required significantly more adjustments $(P<0.001)$. Conclusions: $\mathrm{CAD} / \mathrm{CAM}$-fabricated wax patterns showed significantly higher retention for implant-supported cement-retained frameworks; this could be a valuable help when there are limitations in the retention of single-unit implant restorations.

Key words: Computer-aided design/computer-aided manufacturing, dental implant, retention, wax pattern

\section{INTRODUCTION}

Among various material options, metal ceramic restorations are still the most widely used options for fabricating implant-supported restorations. ${ }^{[1]}$ These restorations could be either screw or cement retained. ${ }^{[2]}$ Nowadays, cement-retained restorations are relatively popular because the rates of prosthetic complications and implant survival compare favorably with cement-retained prostheses. ${ }^{[3,4]}$ The

\begin{tabular}{|l|l|}
\hline \multicolumn{2}{|c|}{ Access this article online } \\
\hline Quick Response Code: \\
\hline
\end{tabular}

success of implant therapy depends not only on osseointegration of implants but also on prosthetic factors including maintenance of the restorations' integrity and retention. ${ }^{[5]}$

The conventional way of fabricating metal substructure is lost wax technique. ${ }^{[6]}$ Wax has been chosen for this process because it can be well manipulated, precisely

This is an open access article distributed under the terms of the Creative Commons Attribution-NonCommercial-ShareAlike 3.0 License, which allows others to remix, tweak, and build upon the work non-commercially, as long as the author is credited and the new creations are licensed under the identical terms.

For reprints contact: reprints@medknow.com

How to cite this article: Alikhasi M, Rohanian A, Ghodsi S, Kolde AM. Digital versus conventional techniques for pattern fabrication of implant-supported frameworks. Eur J Dent 2018;12:71-6.

DOI: 10.4103/ejd.ejd_314_17 
shaped, and completely eliminated from the mold by heating. ${ }^{[7]}$ Fabrication of wax pattern is the most crucial and labor-intensive step in making metal ceramic restoration. With the advent of computer-aided design/computer-aided manufacturing (CAD/CAM) and rapid prototyping (RP) technologies, human errors decreased, processes were simplified, and production rates increased. ${ }^{[8,9]}$ The introduction and application of CAD/CAM in finite element analyses provided valuable information on the pattern of stress distribution in complicate structures. With increasing application of computer in medicine, CAD/CAM base systems have been widely used in the surgical procedure and fabrication of precise equipment. These techniques have three steps of scanning the master model with a three-dimensional (3D) optical scanner, designing the pattern with specialized CAD software, and fabricating the wax model (using either RP techniques or milling machine in CAD/CAM system) $\cdot{ }^{[10]}$

The application of CAD/CAM systems offers the advantages of high-quality restoration by using prefabricated blocks of material, reducing production cost, labor, and time, ${ }^{[11]}$ enhancing the accuracy, decreasing the errors, ${ }^{[12]}$ automatic accurate margin detection, and automatic restoration designing facilities. ${ }^{[13]} \mathrm{RP}$ technology also has high production rate (up to 150 unit per hour), the quality control of wax framework, and reduction in material waste, spruing time, and finishing work needed on frameworks. ${ }^{[10,14]}$ Although CAD/CAM technology could be used for milling framework or monolithic restorations, using full digital workflow for long-span restorations is still with doubt. ${ }^{[15-17]}$ Therefore, conventional casting technique is still being in use in dental laboratories. Successful application of CAD/CAM or RP technologies for fabrication of removable partial denture frameworks has been confirmed. However, few studies have investigated the influence of wax pattern fabrication method on final fixed restoration properties. ${ }^{[18,19]}$

As the biomechanical problems account for the major part of implant failures, ${ }^{[20]}$ controlling the stress distribution (compressive, tensile, or shear) and increasing the stability and preciseness of implant-supported restorations could guarantee the long-term clinical results. Finite element and von Mises analyses confirmed the effect of implant-abutment connection type (screw vs. cement), ${ }^{[21]}$ number and distribution of implant fixtures, size and type of individual components, abutment shape, ${ }^{[22]}$ implant inclination, ${ }^{[20]}$ length, diameter, and surface characteristics, ${ }^{[23]}$ bone quantity and quality, and restorative materials, ${ }^{[24]}$ on stress distribution to implant and bone-implant interface.

Retention is one of the indices reflecting the precision and adaptation of a restoration on the related abutment. This characteristic has been investigated in several studies. The studies on the retention of implant- or tooth-supported crowns cemented with zinc phosphate (ZP) cement are summarized in Table 1. ${ }^{[25-39]}$ The effect of abutment height, diameter, and surface characteristics and cement type and thickness on the retention of implant- or tooth-supported restorations has been evidenced. ${ }^{[25,40,41]}$ The present study aimed at investigating if wax patterns fabricated by CAD/CAM or RP systems could improve retention value in implant-supported single-unit restorations compared to conventional wax-up method. The null hypothesis was that there was no significant difference in the quantity of retention among these three groups.

\section{MATERIALS AND METHODS}

By considering a standard deviation of 7.33 and significance level of 0.05 , PASS 11 software (NCSS PASS, Statcon GmbH, Witzenhausen, Germany) (one-way analysis of variance [ANOVA]) was applied to determine the minimum sample size to achieve $86 \%$ power. Thirty-six acrylic resin (Cold-cure acrylic for repair, Acropars, Iran) cubes were fabricated in special metal molds and 36 implant analogs (Fixture Lab analogue, Ufit Dental implant system, South Korea) were mounted vertically in these cubes with acrylic resin (Acrylic resin for patterns, GC America Inc., Alsip, IL, USA). Straight abutments (Solid abutment, Ufit Dental implant system, South Korea) with 5.5-mm length and $6^{\circ}$ of convergence were secured in the fixture analogs following manufacturer's recommendations. Impression coping was used on dental surveyor (Ney Dental International, Bloomfield, CT, USA) as a guide to ensure parallel mounting of each specimen. Based on wax pattern fabrication method, the specimens were randomly divided into three groups $(n=12)$. Two groups of the abutments were sprayed with scan spray (Powder scan spray, Vita, North America) and optically scanned (3Shape D810; 3Shape, Copenhagen K, Denmark) to make a digital model of abutments. For patterns fabrication, simulated die spacer was set at $30 \mu \mathrm{m}$, started $0.5 \mathrm{~mm}$ from the margin ${ }^{[42]}$ and patterns were designed in the software. Then, CAD/CAM wax patterns were produced (Yeti, Dentalproduct, $\mathrm{GmbH}$, Engen, Germany) through a subtractive method in 
Alikhasi, et al.: The fabrication methods of implant frameworks

\begin{tabular}{|c|c|c|c|c|c|}
\hline Reference & Abutment type & Fabrication method & Characteristic & Abutment height $(\mathrm{mm})$ & Retention \\
\hline Covey et al. ${ }^{[25]}$ & Nobel Biocare & Gold cylinder & CeraOne & 5 & $600 \mathrm{~N}$ \\
\hline Kent et al. ${ }^{[26]}$ & Nobel Biocare & Gold cylinder & CeraOne & 5 & $599.19 \mathrm{~N}$ \\
\hline Clayton et al..$^{[27]}$ & Nobel Biocare & Gold cylinder & CeraOne & 3.7 & $452.2 \mathrm{~N}$ \\
\hline Yeung et al. ${ }^{[28]}$ & Nobel Biocare & Gold cylinder & CeraOne & & $344.21 \mathrm{~N}$ \\
\hline \multirow[t]{2}{*}{ Mayata-Tovalino et al..$^{[29]}$} & Nobel Biocare & Not mentioned & CeraOne & 5.5 & $459.62 \mathrm{~N}$ \\
\hline & & & Solid abutment & & $459.62 \mathrm{~N}$ \\
\hline Li et al. ${ }^{[30]}$ & $\begin{array}{l}\text { Nobel Biocare, } \\
\text { Steri-Oss }\end{array}$ & Conventional wax-up & & 3.8 & $0.731 \mathrm{MPa}$ \\
\hline Pan and $\operatorname{Lin}^{[31]}$ & $\begin{array}{l}\text { Nobel Biocare, } \\
\text { Steri-Oss }\end{array}$ & Conventional wax-up & & 3.8 & $1.225 \mathrm{MPa}$ \\
\hline Tan et al. ${ }^{[32]}$ & Biomet 3i & Conventional wax-up & & 7 & $158.8 \mathrm{~N}$ \\
\hline \multirow[t]{4}{*}{ Bernal et al. ${ }^{[33]}$} & & Conventional wax-up & $30^{\circ}$ taper & 8 & $200.06 \mathrm{~N}$ \\
\hline & & & & 4 & $105.91 \mathrm{~N}$ \\
\hline & & & $20^{\circ}$ taper & 8 & $374.61 \mathrm{~N}$ \\
\hline & & & & 4 & $225.55 \mathrm{~N}$ \\
\hline \multirow[t]{2}{*}{ Matani et al. ${ }^{[34]}$} & Uniti implant & Conventional wax-up & $3.7 \mathrm{~mm}$ diameter & 8 & $464.2 \mathrm{~N}$ \\
\hline & & & $6 \mathrm{~mm}$ diameter & 8 & $667.4 \mathrm{~N}$ \\
\hline Nejatidanesh et al..$^{[35]}$ & ITI solid abutment & Prefabricated burn-out cap & $8^{\circ}$ taper & 5.5 & $267.62 \mathrm{~N}$ \\
\hline Swift et al. ${ }^{[36]}$ & Molar tooth & Conventional wax-up & $4-8^{\circ}$ taper & & $587 \mathrm{~N}$ \\
\hline Mausner et al. ${ }^{[37]}$ & Premolar tooth & Conventional wax-up & $6-10^{\circ}$ taper & 5 & $383 \mathrm{~N}$ \\
\hline Gorodovsky and Zidan ${ }^{[38]}$ & Molar tooth & Conventional wax-up & $8^{\circ}$ taper & 4.5 & $3.08 \mathrm{MPa}$ \\
\hline Darveniza et al. ${ }^{[39]}$ & Molar tooth & Conventional wax-up & $4-6^{\circ}$ taper & 3 & $207 \mathrm{~N}$ \\
\hline
\end{tabular}

milling machine (CORiTEC 450i; imes-icore $\mathrm{GmbH}$, Eiterfeld, Germany). The RP wax patterns were also fabricated (Labcast wax, Solidscape material, Cimetrix, Montreal, Canada) in an additive inkjet-based process by R66PLUS system (Solidscape Inc., Merrimack, $\mathrm{NH}, \mathrm{USA}$ ).

To standardize the contour and thickness of wax patterns in all the three groups, a silicon index was made from the first CAD/CAM wax pattern and was used as an index for conventional wax-up method. Two layers of die spacer (Pico-fit; Renfert $\mathrm{GmbH}$, Hilzingen, Germany) were applied directly on each abutment wall with a total thickness of $30 \mu$ up to $0.5 \mathrm{~mm}$ from the finishing line. Dip wax technique was used for conventional wax-up procedure. Inlay wax (GEO classic, Renfert GmbH, Hilzingen, Germany) was added and shaped by electric waxing instruments (Waxelectric II, Renfert $\mathrm{GmbH}$, Hilzingen, Germany) according to the index. A hook with an internal diameter of $5 \mathrm{~mm}$ was designed on the top of each specimen for attachment to universal testing machine for tensile resistance test.

All wax patterns were invested and cast by $\mathrm{Ni}-\mathrm{Cr}$ Alloy (4all ${ }^{\circledR}$, Ivoclar Vivadent, Schaan, Liechtenstein) with electric induction casting procedure. The internal surfaces of all frameworks were particle abraded with $50 \mu \mathrm{m}$ particles of aluminum oxide (Basic master;
Renfert $\mathrm{GmbH}$, Hilzingen, Germany) at a pressure of $0.3 \mathrm{MPa}$. Internal surfaces were evaluated by some binocular loups (HEINE HR-C 2.5x, HEINE ${ }^{\circledR}$, Herrsching, Germany) and visible nodules were removed with a tungsten carbide bur (No. H71EF; Brasseler GmbH and Go. KG, Komet, Siegel, Germany). A single expert-reliable technician performed all the laboratory procedures. In order to detect interferences, the internal surface of each framework was checked with a disclosing agent (Occlude indicator spray, Pascal International Inc., Seattle, Washington) and adjusted by the same reliable dentist. The adjustment times were recorded for each specimen and statistically analyzed with nonparametric Kruskal-Wallis test with the significance level of $P<0.05$.

Frameworks were cemented on the corresponding abutments with ZP cement (Hoffmann Dental Manufacture $\mathrm{GmbH}$, Halle, Germany) by standard procedure. Finger pressure was continued for $10 \mathrm{~min}$ for final setting of the cement. Excess material was removed by a dental explorer. In order to simulate oral condition and aging process, the framework/abutment/acrylic resin block assemblies were stored at $37^{\circ} \mathrm{C}$ and $100 \%$ humidity in an incubator machine for $24 \mathrm{~h}$ and thermocycled (TC-300, Vafaei industrial, Iran) for 5000 cycles, $5^{\circ} \mathrm{C}-55^{\circ} \mathrm{C}$, with a 30-s dwell time equivalent to 6 months of clinical application. Universal testing machine 
(Zwick/Roell ProLine Z050, Berlin, Germany) was set at a $0.5 \mathrm{~mm} / \mathrm{min}$ crosshead speed, and pull-out test was used to evaluate retention of the individual restoration. The data were recorded in Newton $(\mathrm{N})$. Statistical analysis was performed by ANOVA and post hoc Tukey test (the level of significance was set at $P<0.05)$.

\section{RESULTS}

The number of adjustment times for each specimen is shown in Table 2. The result of Kruskal-Wallis test showed significant difference among the three groups $(P<0.001)$. The CAD/CAM group required significantly more adjustments than the two other groups, while RP and conventional groups did not differ in needed adjustments according to median and interquartile range $(P=0.986)$.

The retention mean values were measured as $680.36 \pm 21.93 \mathrm{~N}$ for CAD/CAM group, $440.48 \pm 85.98 \mathrm{~N}$ for RP group, and 407.23 $\pm 67.48 \mathrm{~N}$ for conventional group. The interval plot for retention ( $95 \%$ confidence interval for the mean) is shown in Graph 1. One-way ANOVA test revealed significant differences among the groups $(P<0.001)$. The post hoc Tukey test showed that retention value in CAD/CAM group was significantly greater than that of the other groups $(P<0.001)$. There was no significant difference between RP and conventional wax-up groups $(P=0.54)$.

\section{DISCUSSION}

Evidence shows that the abutment properties, quantity of cement space, and type of cement affect retention values of implant- or tooth-supported restorations. . $^{[25,40,41]}$ This study was conducted to compare the effect of different methods of wax pattern fabrication on the retention value of implant-supported frameworks and showed that wax pattern fabrication method could also affect retention of related restorations. Therefore, the null hypothesis was rejected.

Several materials and methods have been introduced for fabrication of fixed dental or implant restorations,

\begin{tabular}{|c|c|c|c|c|c|}
\hline Group & $n$ & Mean & IQR & Minimum & Maximum \\
\hline CAD/CAM & 12 & 5 & 2 & 4 & 7 \\
\hline Rapid prototyping & 12 & 1 & 1 & 0 & 3 \\
\hline Conventional & 12 & 1 & 3 & 0 & 4 \\
\hline
\end{tabular}

all aimed at improving the accuracy, velocity, and quality of final output. The conventional method is still the gold standard in marginal and internal adaptation according to Leong et al., Harris and Wickens, Vojdani et al., and Mansour et al. ${ }^{[43-46]}$ However, introduction of computerized methods, with their capacity to eliminate the human error, has affected dental practice. The present study showed no significant difference between retention of RP and conventional method $(P=0.54)$; however, frameworks fabricated with CAD/CAM-milled wax patterns had significantly higher retention values $(P<0.001)$. The results suggest that when the clinician decides to use cement-retained restoration on implant, and other clinical situations are not in favor of good retention, CAD/CAM waxing method is a reliable option. With the advancement of technology in the field of 3D printers, improving the results of RP system to profit the advantages of this new technology is promising. It has been shown that RP method decreased time and material waste compared to CAD/CAM milling. ${ }^{[10,14]}$

$\mathrm{ZP}$ cement is a reliable, nonadhesive, conventional cement that exhibits good compression and tensile resistance when used at a thickness of $30 \mu \mathrm{m} .{ }^{[40]}$ The luting property of ZP cement is achieved mainly from mechanical interlocking. ${ }^{[41]}$ According to the scientific evidence, the retention of implant-/tooth-supported crowns cemented by ZP cement generally ranged between 200 and $600 \mathrm{~N}_{,}^{[25-27,36-39,47]}$ and there is a little difference in retentive values between the implant or natural abutments. Dislodging forces in oral cavity have been reported to range from 60 to $200 \mathrm{~N}$ in anterior area and $300-800 \mathrm{~N}$ in posterior area. ${ }^{[4]}$ Therefore, ZP cement provides generally acceptable retention for implant-supported fixed restoration, even in decreased abutment height or increased

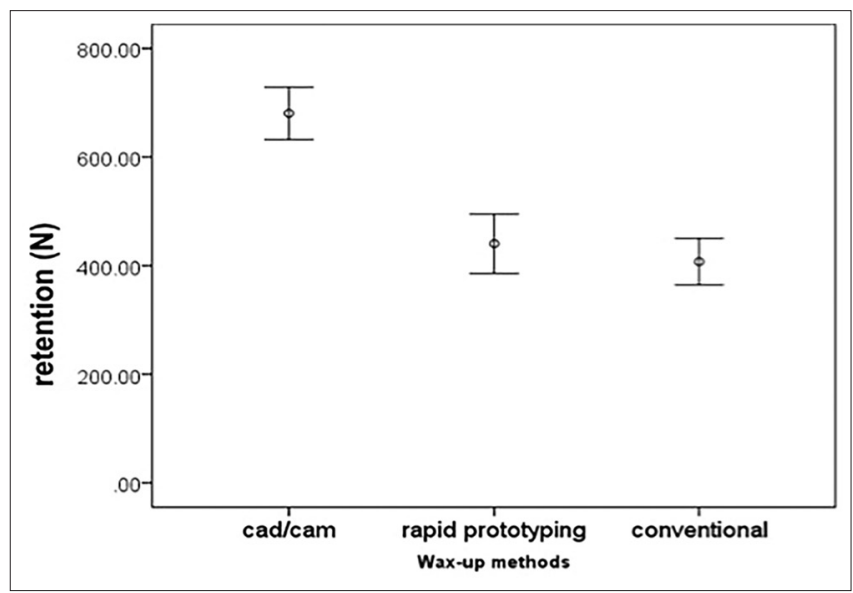

Graph 1: The interval plot for the retention tests (95\% confidence interval for the mean) 
abutment taper. ${ }^{[27,30,31,33,38,39]}$ However, most of the investigations regarding retentive values are performed with conventional wax-up method, other than those applied prefabricated burn-out or gold cylinders. The present study compared different methods of wax pattern fabrication and showed that RP and conventional groups provided clinically acceptable retention quantities, while the CAD/CAM group showed considerably higher retention value.

Better fitness of CAD/CAM specimens necessitated more adjustment times that may be time consuming in clinical practice. Increasing the cement space may be considered rational, provided that the retention is not sacrificed. According to Torabi and Azarian, ${ }^{[42]}$ increasing the spacer thickness up to $40 \mu$ would not cause significant change in retention. However, further studies are encouraged to evaluate the effect of cement space on the retentive value of computerized methods for fabricating dental restorations. Further studies are also suggested to evaluate the long-term clinical results of different fabrication methods and measure the retention under nonaxial forces that are the prominent types of exerted functional loads.

\section{CONCLUSIONS}

Within the limitation of this study, the following conclusions could be made:

1. By application of CAD/CAM technique for wax pattern fabrication, there was a significantly increased retention of implant-supported frameworks compared to conventional wax-up method $(P<0.001)$

2. Retention of frameworks cast from CAD/CAM wax-up procedure was significantly more than those cast from rapid prototyped wax patterns $(P<0.001)$

3 . There was no significant difference in retentive values between frameworks cast from conventional and rapid prototyped wax patterns $(P=0.54)$

4. The retentions achieved by all three groups were clinically acceptable

5. Frameworks cast from CAD/CAM waxing preparation required significantly more adjustments compared to conventional or rapid prototyped wax patterns $(P<0.001)$.

\section{Acknowledgment}

The authors would like to thank the vice-chancellery of Tehran University of Medical Sciences and Health Services, Tehran, Iran, for supporting the research (Grant\# 29353).
Financial support and sponsorship

This study was financially supported by Tehran University of Medical Sciences.

\section{Conflicts of interest}

There are no conflicts of interest.

\section{REFERENCES}

1. Pettenò D, Schierano G, Bassi F, Bresciano ME, Carossa S. Comparison of marginal fit of 3 different metal-ceramic systems: An in vitro study. Int J Prosthodont 2000;13:405-8.

2. Kokubo Y, Kano T, Tsumita M, Sakurai S, Itayama A, Fukushima S, et al. Retention of zirconia copings on zirconia implant abutments cemented with provisional luting agents. J Oral Rehabil 2010;37:48-53.

3. Shadid R, Sadaqa N. A comparison between screw- and cement-retained implant prostheses. A literature review. J Oral Implantol 2012;38:298-307.

4. Lemos CA, de Souza Batista VE, Almeida DA, Santiago Júnior JF, Verri FR, Pellizzer EP, et al. Evaluation of cement-retained versus screw-retained implant-supported restorations for marginal bone loss: A systematic review and meta-analysis. J Prosthet Dent 2016;115:419-27.

5. Breeding LC, Dixon DL, Bogacki MT, Tietge JD. Use of luting agents with an implant system: Part I. J Prosthet Dent 1992;68:737-41.

6. Quante K, Ludwig K, Kern M. Marginal and internal fit of metal-ceramic crowns fabricated with a new laser melting technology. Dent Mater 2008;24:1311-5.

7. Rosenstiel SF, Land MF, Fujimoto J. Contemporary Fixed Prosthodontics. $4^{\text {th }}$ ed. St. Louis: Mosby; 2006. p. 562-79.

8. Williams RJ, Bibb R, Eggbeer D, Collis J. Use of CAD/CAM technology to fabricate a removable partial denture framework. J Prosthet Dent 2006;96:96-9.

9. Wu M, Tinschert J, Augthun M, Wagner I, Schädlich-Stubenrauch J, Sahm PR, et al. Application of laser measuring, numerical simulation and rapid prototyping to titanium dental castings. Dent Mater 2001;17:102-8.

10. Azari A, Nikzad S. The evolution of rapid prototyping in dentistry: A review. Rapid Prototyp J 2009;15:216-25.

11. Strub JR, Rekow ED, Witkowski S. Computer-aided design and fabrication of dental restorations: Current systems and future possibilities. J Am Dent Assoc 2006;137:1289-96.

12. Abduo J, Lyons K, Swain M. Fit of zirconia fixed partial denture: A systematic review. J Oral Rehabil 2010;37:866-76.

13. Tan PL, Gratton DG, Diaz-Arnold AM, Holmes DC. An in vitro comparison of vertical marginal gaps of CAD/CAM titanium and conventional cast restorations. J Prosthodont 2008;17:378-83.

14. Liu Q, Leu MC, Schmitt SM. Rapid prototyping in dentistry: Technology and application. Int J Adv Manuf Technol 2006;29:317-35.

15. Gherlone E, Capparé P, Vinci R, Ferrini F, Gastaldi G, Crespi R, et al. Conventional versus digital impressions for "All-on-four" restorations. Int J Oral Maxillofac Implants 2016;31:324-30.

16. Papaspyridakos P, Gallucci GO, Chen CJ, Hanssen S, Naert I, Vandenberghe B, et al. Digital versus conventional implant impressions for edentulous patients: Accuracy outcomes. Clin Oral Implants Res 2016;27:465-72.

17. Mangano FG, Veronesi G, Hauschild U, Mijiritsky E, Mangano C. Trueness and precision of four intraoral scanners in oral implantology: A Comparative in vitro study. PLoS One 2016;11:e0163107.

18. Kazemi M, Pornasrollah A, Allahyari S, Jalali H. Retention of castings fabricated by plastic coping and direct wax up for single crown and bridge in different implant systems. J Dent Med 2015;28:86-94.

19. Williams RJ, Bibb R, Rafik T. A technique for fabricating patterns for removable partial denture frameworks using digitized casts and electronic surveying. J Prosthet Dent 2004;91:85-8.

20. Cicciu M, Bramanti E, Matacena G, Guglielmino E, Risitano G. FEM evaluation of cemented-retained versus screw-retained dental implant single-tooth crown prosthesis. Int J Clin Exp Med 2014;7:817-25.

21. Cicciù M, Bramanti E, Cecchetti F, Scappaticci L, Guglielmino E, Risitano G, et al. FEM and von Mises analyses of different dental implant shapes for masticatory loading distribution. Oral 


\section{Alikhasi, et al.: The fabrication methods of implant frameworks}

Implantol (Rome) 2014;7:1-0.

22. Cicciù M, Cervino G, Bramanti E, Lauritano F, Lo Gudice G, Scappaticci L, et al. FEM analysis of mandibular prosthetic overdenture supported by dental implants: Evaluation of different retention methods. Comput Math Methods Med 2015;2015:943839.

23. Bramanti E, Cervino G, Lauritano F, Fiorillo L, D'Amico C, Sambataro S, et al. FEM and von Mises analysis on prosthetic crowns structural elements: Evaluation of different applied materials. ScientificWorldJournal 2017;2017:1029574.

24. Cicciù M, Beretta M, Risitano G, Maiorana C. Cemented-retained vs. screw-retained implant restorations: An investigation on 1939 dental implants. Minerva Stomatol 2008;57:167-79.

25. Covey DA, Kent DK, St. Germain HA Jr., Koka S. Effects of abutment size and luting cement type on the uniaxial retention force of implant-supported crowns. J Prosthet Dent 2000;83:344-8.

26. Kent DK, Koka S, Froeschle ML. Retention of cemented implant-supported restorations. J Prosthodont 1997;6:193-6.

27. Clayton GH, Driscoll CF, Hondrum SO. The effect of luting agents on the retention and marginal adaptation of the ceraOne implant system. Int J Oral Maxillofac Implants 1997;12:660-5.

28. Yeung TC, Lai YL, Hsieh YL, Lee SY. The effect of cement and venting design on the retentive strength and marginal adaptation of CeraOne implant prostheses. Chin Dent J 2005;24:95-100.

29. Mayata-Tovalino FR, Ccahuana-Vasquez VZ, Rosas-Diaz JC. Removal force of cast copings to abutments with three luting agents. J Dent Implant 2015;5:25-30.

30. Li TH, Lin DM, Pan YH. Retention and marginal adaptation of luting agents on dental implant-supported prostheses. Taiwan J Oral Maxillofac Surg 2014;25:88-99.

31. Pan YH, Lin CK. The effect of luting agents on the retention of dental implant-supported crowns. Chang Gung Med J 2005;28:403-10.

32. Tan KM, Masri R, Driscol CF, Limkangwalmongkol P, Romberg E. Effect of axial wall modification on the retention of cement-retained, implant-supported crowns. J Prosthet Dent 2012;107:80-5.

33. Bernal G, Okamura M, Muñoz CA. The effects of abutment taper, length and cement type on resistance of dislodgement of cement-retained, implant-supported restorations. J Prosthodont 2003;12:111-5.

34. Matani JD, Parulekar N, Kheur M, Jambhekar S, Supriya MK. Retention of metal crowns luted to implant abutments of two different diameters using different luting agents. Int J Prosthodont Restor Dent 2012;2:96-100.

35. Nejatidanesh F, Savabi O, Ebrahimi M, Savabi G. Retentiveness of implant-supported metal copings using different luting agents. Dent Res J (Isfahan) 2012;9:13-18.

36. Swift EJ Jr., Lloyd AH, Felton DA. The effect of resin desensitizing agents on crown retention. J Am Dent Assoc 1997;128:195-200.

37. Mausner IK, Goldstein GR, Georgescu M. Effect of two dentinal desensitizing agents on retention of complete cast coping using four cements. J Prosthet Dent 1996;75:129-34.

38. Gorodovsky S, Zidan O. Retentive strength, disintegration, and marginal quality of luting cements. J Prosthet Dent 1992;68:269-74

39. Darveniza M, Basford KE, Meek J, Stevens L. The effects of surface roughness and surface area on the retention of crowns luted with zinc phosphate cement. Aust Dent J 1987;32:446-57.

40. Schiessl C, Schaefer L, Winter C, Fuerst J, Rosentritt M, Zeman F, et al. Factors determining the retentiveness of luting agents used with metal- and ceramic-based implant components. Clin Oral Investig 2013;17:1179-90.

41. Ayad MF, Rosenstiel SF, Salama M. Influence of tooth surface roughness and type of cement on retention of complete cast crowns. J Prosthet Dent 1997;77:116-21.

42. Torabi K, Azarian M. Study of the effect of die spacing (Cement Space) on cast crown retention. J Dent 2003;4:16-23.

43. Harris IR, Wickens JL. A comparison of the fit of spark-eroded titanium copings and cast gold alloy copings. Int J Prosthodont 1994;7:348-55.

44. Leong D, Chai J, Lautenschlager E, Gilbert J. Marginal fit of machine-milled titanium and cast titanium single crowns. Int J Prosthodont 1994;7:440-7.

45. Vojdani M, Torabi K, Farjood E, Khaledi A. Comparison the marginal and internal fit of metal copings cast from wax patterns fabricated by CAD/CAM and conventional wax up techniques. J Dent (Shiraz) 2013;14:118-29.

46. Mansour A, Ercoli C, Graser G, Tallents R, Moss M. Comparative evaluation of casting retention using the ITI solid abutment with six cements. Clin Oral Implants Res 2002;13:343-8.

47. Augstin-Panadero R, Fons-Font A, Roman-Rodriguez JL, Granell-Ruiz M, del Rio-Highsmith J, Sola-Ruiz MF, et al. Zirconia versus metal: A preliminary comparative analysis of ceramic veneer behavior. Int J Prosthodont 2012;25:294-300. 